\title{
Absolute quantification of terpenes in conifer-derived essential oils and their antibacterial activity
}

\author{
Martina Delia Allenspach ${ }^{1}$, Claudia Valder ${ }^{2}$ and Christian Steuer ${ }^{1 *}$
}

\begin{abstract}
A simple, robust, and precise method for the absolute quantification of the terpenes a-pinene, camphene, $\beta$ pinene, 3-carene, limonene, bornyl acetate, $\beta$-caryophyllene, and borneol was developed using gas chromatography coupled to a flame ionization detector (GC-FID) and validated according to the International Council for Harmonization of Technical Requirements for Pharmaceuticals for Human Use. The GC-FID method shows high accuracy (91-105\%) and low imprecision (< 7.6\%) for all terpenes at quality control (QC) low, medium, and high level. The curves are linear with strong correlation $\left(R^{2} \geq 0.999\right)$ for all terpenes. Additionally, the relative response factor (RRF) for each terpene is calculated. The method was validated in terms of specificity, linearity, accuracy, precision, LOD, LOQ, stability tests, and carry-over. The method was successfully applied to quantify the selected terpenes in conifer-derived essential oils (CEOs). The total amount of terpenes ranged from 6.3 to $11.8 \mathrm{mM}$. Additionally, the CEOs were screened in vitro for the antibacterial activity against E. coli and S. aureus using the broth microdilution method to determine the minimum inhibitory concentration (MIC). All the CEOs showed antibacterial activity in the concentration from 0.3 to $50 \mu \mathrm{g} / \mathrm{mL}$ (S. aureus) and 1.2 to $50 \mu \mathrm{g} / \mathrm{mL}$ (E. coli), respectively). CEO14 showed the most effective antibacterial activity of the entire tested CEOs (MIC values $0.3 \mu \mathrm{g} / \mathrm{mL}$ (S. aureus);

$1.2 \mu \mathrm{g} / \mathrm{mL}$ (E. coli)). Our results suggest that the terpenoid profile should be considered for a comprehensive evaluation of the antibacterial activity, as none of the single compounds seems to be fully responsible for antibacterial activity.
\end{abstract}

Keywords: Conifer-derived essential oil, Terpenes, Absolute quantification, Method development, Antibacterial activity

\section{Introduction}

Essential oils (EOs) are mixtures of natural chemical substances mainly categorized into monoterpenes, sesquiterpenes, and their oxygenated derivatives at different concentrations, which are responsible for their biological and physiological activities such as antimicrobial, anticarcinogenic, or antioxidative effects. EOs are the product of the secondary metabolism of the plant and are widely used in folk and evidence-

\footnotetext{
* Correspondence: christian.steuer@pharma.ethz.ch

'Institute of Pharmaceutical Sciences, ETH Zürich, Vladimir-Prelog-Weg 4, CH-8093 Zürich, Switzerland

Full list of author information is available at the end of the article
}

based medicine as well in drug, perfume, and food industries. Due to the increased resistance of microorganism against conventional antibiotics, the focus on EOs as a new antibacterial alternative is established (Başer and Buchbauer 2016; Sarac et al. 2014; Chouhan et al. 2017). Many EOs were screened against a panel of microorganism to evaluate the antibacterial activity (Hong et al. 2004). The chemical composition of the EOs and their amount of compounds define their antibacterial activity (Sarac et al. 2014). The microorganisms are susceptible to various terpenes since investigated EOs differ in their antibacterial profile. In general, the oxygenated terpenes
Springer Open

(c) The Author(s). 2020 Open Access This article is licensed under a Creative Commons Attribution 4.0 International License, which permits use, sharing, adaptation, distribution and reproduction in any medium or format, as long as you give appropriate credit to the original author(s) and the source, provide a link to the Creative Commons licence, and indicate if changes were made. The images or other third party material in this article are included in the article's Creative Commons licence, unless indicated otherwise in a credit line to the material. If material is not included in the article's Creative Commons licence and your intended use is not permitted by statutory regulation or exceeds the permitted use, you will need to obtain permission directly from the copyright holder. To view a copy of this licence, visit http://creativecommons.org/licenses/by/4.0/. 
exhibited better antibacterial activity than the hydrocarbon congeners (Nazzaro et al. 2013; Guimaraes et al. 2019; Iseppi et al. 2019; Dahham et al. 2015; Hong et al. 2004). As described previously, terpenes have several targets in the bacterial membrane and in the cytoplasm of bacterial cell (Burt 2004; Nazzaro et al. 2013). Due to the lipophilicity, EOs are capable to incorporate into the bacterial membranes. Consequently, permeability of the membrane is altered, and loss of cell contents can occur which can lead to cell death (Sarac et al. 2014; Burt 2004). Furthermore, the cell membrane and membrane proteins can be damaged or the EO can affect the ATP synthesis so that the intracellular ATP pool is reduced. Additionally, the EOs can act intracellular and denature cellular proteins or interfere with the protein synthesis. Due to the high variety of compounds present in the EOs, the antibacterial activity cannot be induced by a single mode of action (Nazzaro et al. 2013).

There are several published studies of conifer-derived essential oils (CEO), which have already analyzed the chemical composition and evaluated the antibacterial properties against a panel of microorganisms. These publications show that the CEOs are able to inhibit the growth of gram-positive and gram-negative bacteria (Hong et al. 2004; Lee et al. 2009a; Fahed et al. 2017; Bouyahya et al. 2019; Lee et al. 2008; Park and Lee 2011; Pichette et al. 2006; Bagci and Digrak 1996; Lee et al. 2009b). Nevertheless, the majority of these studies did not use a standardized approach for the evaluation of the antibacterial activity. However, using a standardized approach is pivotal to compare the effectiveness of the activity among the several CEOs. For the quantitative determination of the compounds in the EOs, the European Pharmacopeia (chapter 2.8.12) uses the normalization procedure (Ph. Eur.). So far, most CEOs have been quantitatively characterized using the area normalization procedure. It is obvious that this approach has several limitations such as (i) dilution effects are not detectable and (ii) the compounds do not have similar affinity to the detector. Subsequently, biological data is not comparable among EOs. Therefore an absolute quantitative analytical procedure is needed (Bicchi et al. 2008). Even though numerous studies on the determination of EO compounds using internal standard(s) have already been reported, to our knowledge, there are no reports for absolute quantification of terpenes in CEOs using the relative response factor (RRF) by means of gas chromatography coupled to a flame ionization detector (GC-FID) (Demirbolat et al. 2019; Ibrahim et al. 2019; Lim et al. 2019). However, the absolute quantification is crucial for the correct evaluation of biological assays of several CEOs and other pharmacological active medicinal plants. Current studies on Cannabis sativa L. highlighted the importance of terpene fingerprints on the pharmacological activity besides the cannabinoids (Iseppi et al. 2019; Mudge et al. 2019; Russo 2011). Furthermore, absolute quantification, additionally to the relative amount of the chemical composition, is recommended for a proper quality evaluation (Edris 2009).

The present work represents an absolute quantification of terpenes present in CEOs and the evaluation of the antibacterial activity applying standardized approaches. In here, we describe the development and validation of a simple, robust, and precise GC-FID method using cis-3hexenol as internal standard (IS) for the absolute quantification of eight terpenes. In addition, the antibacterial effect of the CEOs against gram-positive and gramnegative bacteria was evaluated applying a standardized assay format. The MIC of the CEOs was correlated to the absolute concentration of single terpenes and to the overall terpenoid content.

\section{Experimental \\ Reagents}

Camphene (95\%), 3-carene (92\%), $\beta$-caryophyllene ( $\geq$ $80 \%)$, dimethyl sulfoxide (DMSO), heptane ( $\geq 99 \%)$, $(-)$ - $\alpha$-pinene $(\geq 99 \%)$, and $(-)-\beta$-pinene $(95 \%)$ were purchased from Sigma-Aldrich. Borneol was provided from Systema Natura GmbH. L-Bornyl acetate and cis-3-hexenol were obtained from Frey + Lau. Ethanol absolute $(\geq$ 99.8\%) was obtained from Fisher Chemical. Limonene (> 95\%) was purchased from Fluka. Ampicillin (Ampicillin stock solution $1 \mathrm{mg} / \mathrm{mL}$ ) and McFarland turbidity standard number 0.5 were provided. Helium 6.0 and Hydrogen 5.0 were purchased from PanGas. BBL ${ }^{\text {TM }}$ Mueller Hinton II Agar and BBL ${ }^{\mathrm{TM}}$ Mueller Hinton II Broth were obtained from Becton, Dickinson and Company. 96 well microplate (PS, V-Bottom) was supplied by Greiner Bio-One. Commercially available essential oils were purchased from different suppliers. A detailed overview and used in-house codes can be found in Supplementary Table 1S.

\section{Chromatographic conditions}

The GC analysis was performed using a Thermo Fisher Scientific Trace Ultra gas chromatograph equipped with a DB-WAX capillary column $(30 \mathrm{~m} \times 0.25 \mathrm{~mm}$ i.d., film thickness $0.25 \mu \mathrm{m})$. The temperature of the injection was $220^{\circ} \mathrm{C}$. The injection volume was $1 \mu \mathrm{L}$ using a split ratio of 1:20 with a split flow of $20 \mathrm{~mL} \mathrm{~min}^{-1}$. Helium was used as carrier gas at a constant flow rate of $1.0 \mathrm{~mL}$ $\min ^{-1}$. The oven temperature was kept at $50^{\circ} \mathrm{C}$ for 15 min and then heated to $200{ }^{\circ} \mathrm{C}$ with $8{ }^{\circ} \mathrm{C} \mathrm{min}^{-1}$ and kept constant at $200^{\circ} \mathrm{C}$ for $4 \mathrm{~min}$. The temperature of the detector was $250{ }^{\circ} \mathrm{C}$. Peaks were identified by comparing the retention times with respective reference 
compounds. The data were acquired with Chrom Card Trace Focus GC (Thermo Fisher scientific, version 2.9).

\section{Method validation}

The developed GC-FID method was validated for specificity, linearity, accuracy, precision, limit of detection (LOD), stability tests, and carry-over according to the International Council for Harmonization of Technical Requirements for Pharmaceuticals for Human Use (ICH) Q2A and Q2B guidelines(International Conference on Harmonization (ICH). Validation of analytical procedures. Text and Methodology Q2 (R1) 1996). For the method validation, separate stock solutions for calibrators (Cal) and quality control (QC) samples consisting of $51.5 \mathrm{mM}$ of camphene, $64.8 \mathrm{mM}$ of borneol, 89 $\mathrm{mM}$ of $\beta$-caryophyllene, $124 \mathrm{mM}$ of limonene, $125 \mathrm{mM}$ of $\alpha$-pinene, $\beta$-pinene, and 3-carene and $253 \mathrm{mM}$ bornyl acetate were dissolved in an ethanol-heptane mixture (Supplementary Table 2S). Serial dilution using heptane was performed to obtain different $\mathrm{Cal}$ and QC concentrations (Supplementary Table 3S and 4S). Cis-3-hexenol was used as IS at a final concentration of $3.0 \mathrm{mM}$. Aliquots were stored at $-20^{\circ} \mathrm{C}$ until processing. Calibration curves were constructed from the ratio of the peak area of the Cal samples to the peak area of the IS versus the ratio of their concentrations. Linearity evaluation of the calibration curve was accomplished by applying the weighted least squares regression model. Daily regression lines $(n=6)$ were used for the back-calculation of the concentration of each Cal. To determine the accuracy and intra- and interday precision (precision was expressed by the relative standard deviation (RSD); $\mathrm{RSD}_{\mathrm{R}} / \mathrm{RSD}_{\mathrm{T}}$ ) of the developed GC-FID method, the Cal and QC samples were analyzed over six consecutive days and QC samples were analyzed in duplicate. Daily regression lines $(n=6)$ were used to calculate the relative response factor (RRF) for each terpene $\mathrm{T}$ (response factor $(\mathrm{RF} T)=$ peak area terpene $\mathrm{T}(\mathrm{PA}) /$ concentration terpene (conc); RRF = RF T/RF IS). Additionally, the accuracy and intra- and interday precision $\left(\mathrm{RSD}_{\mathrm{R}} / \mathrm{RSD}_{\mathrm{T}}\right)$ of the QC samples and the back-calculation of the Cal samples were determined. The LOD for each terpene (signal-to-noise ratio $(\mathrm{S} / \mathrm{N})$ of 3:1) was evaluated manually by serial dilutions of $\mathrm{Cal} 6$. For the limit of quantification (LOQ) predefined goals for accuracy (85-115) and RSD $(<15 \%)$ were set at QC low and QC high level (Armbruster and Pry 2008).

For FT stability testing, the QC med $(n=3)$ was frozen at $-20^{\circ} \mathrm{C}$ and was thawed to room temperature after 24, 48, and 72 (or 120) h (3 FT cycles). Subsequently, the samples were refrozen at $-20^{\circ} \mathrm{C}$. To evaluate the autosampler stability, the processed QC med $(n=3)$ was analyzed at ambient temperatures after $6,9,14$, and $24 \mathrm{~h}$, respectively. For calibration stability, the QC samples (low and high) over the six validation days were inserted into the calibration equation of the first day and the accuracy was calculated.

The long-term stability for the processed Cal and QC samples was demonstrated for QC med for 1 month stored at $-20^{\circ} \mathrm{C}$. The stock solution stabilities for the $\mathrm{Cal}$ samples and the IS were tested after 5 days and after 1 month stored at $5{ }^{\circ} \mathrm{C}$. To determine possible carryover, a blank sample of heptane was injected after the highest $\mathrm{Cal}(\mathrm{Cal} \mathrm{1)}$ and was evaluated for corresponding peaks.

The absolute concentration of the single terpenes was measured using conc $\mathrm{T}=(\mathrm{PA} T / \mathrm{PA}$ IS $) *(1 /$ RRF $\mathrm{T})$ * conc IS.

\section{Sample preparation}

For sample preparation, $20 \mu \mathrm{L}$ of the commercial CEOs (final dilution 1:500) was mixed with $200 \mu \mathrm{L}$ stock solution IS and were diluted with heptane to $10 \mathrm{~mL}$. Subsequently, the samples were analyzed by GC-FID.

\section{Data analysis}

Chrom Card Trace Focus GC (Thermo Fisher scientific, version 2.9) was used for peak integration and quantification of data. All statistical analyses and illustrations were carried out using the GraphPad Prism 8 (version 8.0.0 (224)) software.

\section{Antibacterial activity}

The antibacterial activity of the CEOs was characterized by determination of the minimum inhibitory concentration (MIC). MIC values were determined by a broth microdilution method. The CEOs and the compound bornyl acetate were tested against Escherichia coli ATCC 25922 (E. coli) and Staphylococcus aureus ATCC 27853 (S. aureus).

All tests were performed in Mueller Hinton (MHII) broth media. The bacterial suspensions were adjusted visually to 0.5 McFarland standard turbidity (using bacterial inoculates which are prepared a day before and stored overnight at $37^{\circ} \mathrm{C}$ ) and diluted in $\mathrm{MH}$ II broth medium.

A stock solution of the CEOs with DMSO was prepared $(1: 1, \mathrm{v} / \mathrm{v})$. The solvent for the dilution was DMSO/ $\mathrm{ddH}_{2} \mathrm{O}(1: 1, \mathrm{v} / \mathrm{v})$. A serial doubling dilution of the CEOs using MH II broth medium was prepared in a 96-well microtiter plate with a final DMSO concentration of $5 \%$ (v/v) to obtain CEOs concentration from 50 to $1.56 \mu \mathrm{g} /$ $\mathrm{mL}$ or $0.05 \mu \mathrm{g} / \mathrm{mL}$, respectively. Ampicillin $(1 \mathrm{mg} / \mathrm{mL})$ served as positive control. In each assay, controls of sterility and bacterial growth of the examined strains were used. Each test was carried out in triplicate on each well and repeated at least two times $(n=3)$. The MIC values were determined after $16-24 \mathrm{~h}$ of incubation at $37^{\circ} \mathrm{C}$ 


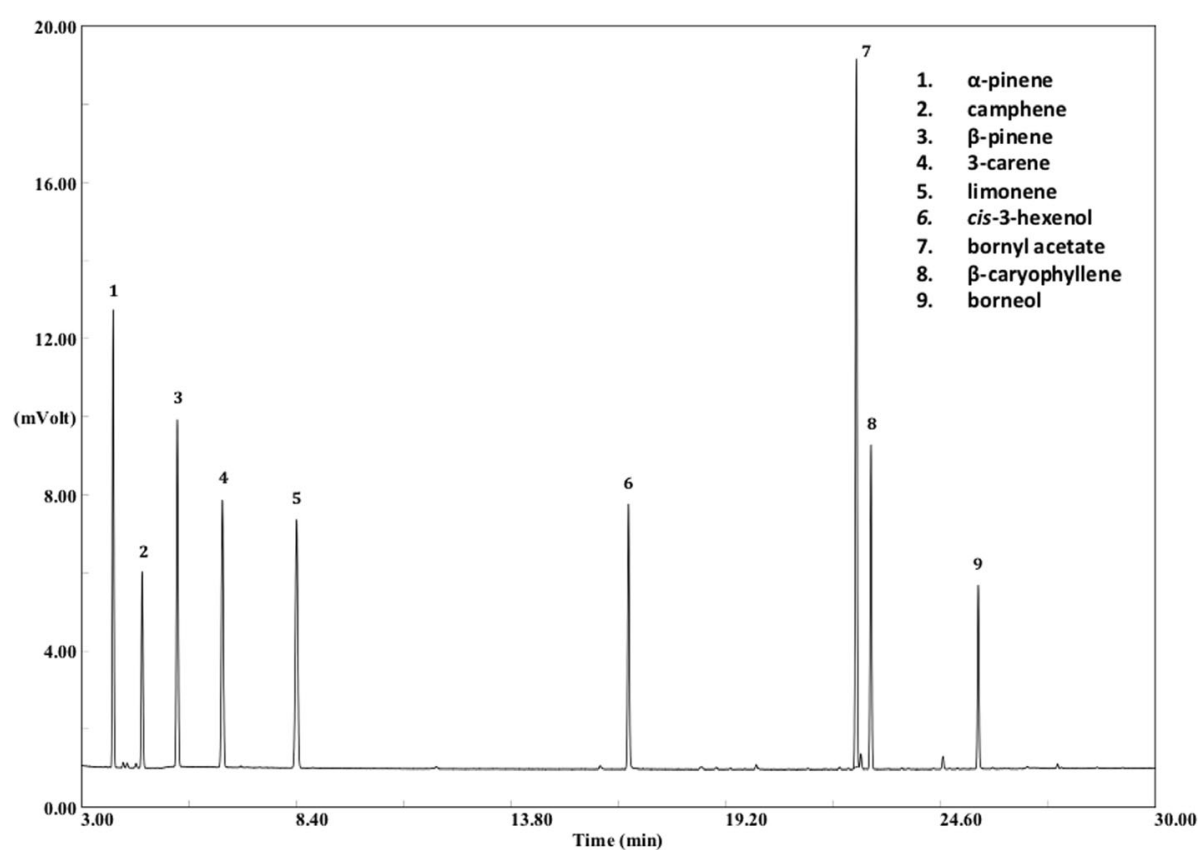

Fig. 1 Chromatographic profiles of GC-FID of Cal 3 showing the eight terpenes with the IS. The chemical structures are provided in Supplementary Table 25

shaking at $200 \mathrm{rpm}$ on a Clim-O-Shake, System Kühner. The MIC is defined as the lowest concentration of the $\mathrm{CEO}$ at which the microorganism does not demonstrate visible growth. The bacterial growth was determined by visual inspection of turbidity.

\section{Results}

A chromatographic procedure to separate $\alpha$-pinene, camphene, $\beta$-pinene, 3-carene, limonene, bornyl acetate, $\beta$-caryophyllene, and borneol was developed and validated. The method provided baseline separation for all terpenes (Fig. 1).The best fit across the calibration range was $1 / \mathrm{x}^{2}$ for $\alpha$-pinene, $\beta$-pinene, 3carene, bornyl acetate, camphene, limonene, $\beta$ caryophyllene, and borneol (Fig. 2). Retention times, RRFs, and LoDs are presented in Table 1. The backcalculated concentrations of the Cal were within \pm $10 \%$ of the nominal concentrations with the weighted
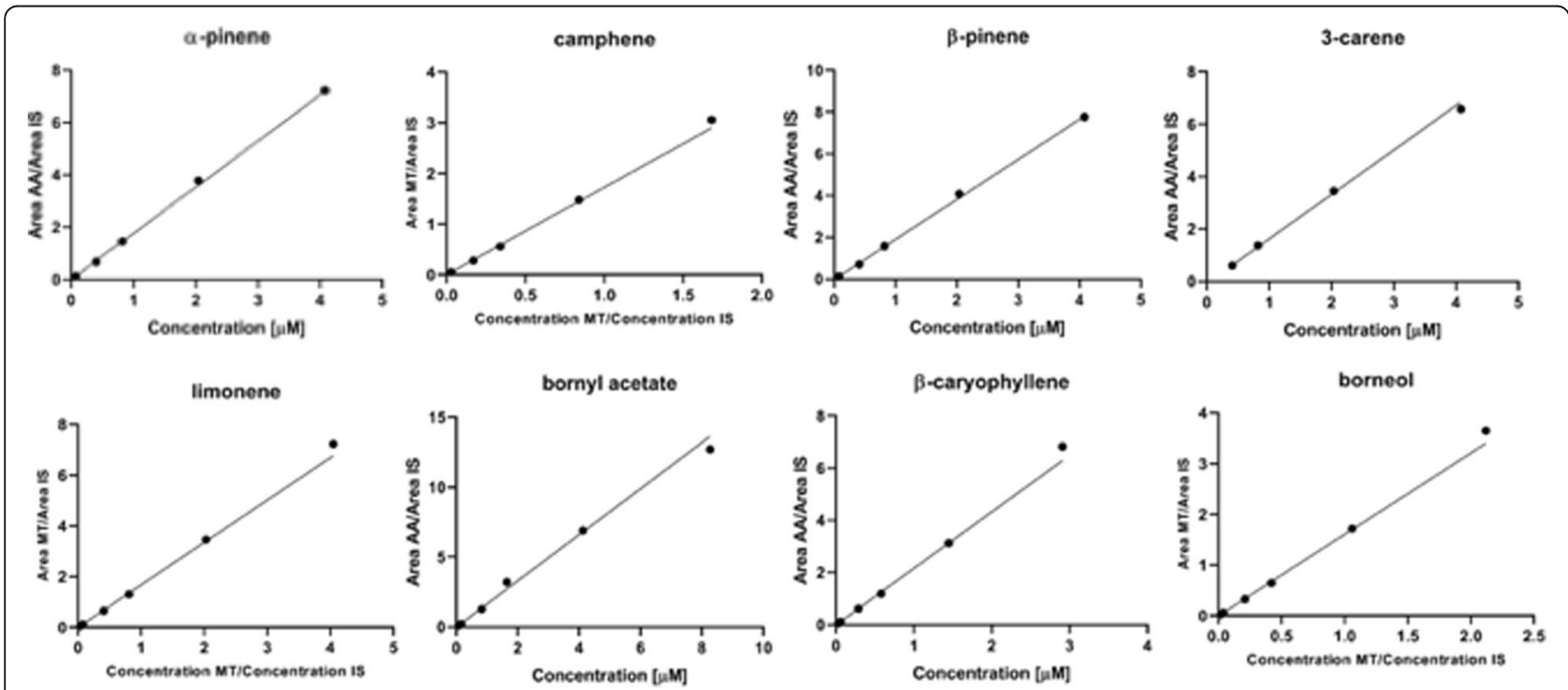

Fig. 2 Calibration curves of the eight terpenes 
Table 1 Method validation data: Retention time, RRF $(n=6)$, LOD, accuracy, intra-day (RSDR) and inter-day precision (RSDT) ( $n=6)$. Data calculated with the RRF are in bold

\begin{tabular}{|c|c|c|c|c|c|c|c|c|c|c|c|c|}
\hline & \multirow{2}{*}{$\begin{array}{l}\text { Retention } \\
\text { time } \\
{[\mathrm{min}]}\end{array}$} & \multirow[t]{2}{*}{ RRF } & \multirow{2}{*}{$\begin{array}{l}\text { LoD } \\
{[\mu M]}\end{array}$} & \multicolumn{3}{|l|}{ QC low } & \multicolumn{3}{|l|}{ QC med } & \multicolumn{3}{|l|}{ QC high } \\
\hline & & & & $\begin{array}{l}\text { Accuracy } \\
(\%)\end{array}$ & $\begin{array}{l}\mathrm{RSD}_{\mathrm{R}} \\
(\%)\end{array}$ & $\begin{array}{l}\mathrm{RSD}_{\mathrm{T}} \\
(\%)\end{array}$ & $\begin{array}{l}\text { Accuracy } \\
(\%)\end{array}$ & $\begin{array}{l}\mathrm{RSD}_{\mathrm{R}} \\
(\%)\end{array}$ & $\begin{array}{l}\mathrm{RSD}_{\mathrm{T}} \\
(\%)\end{array}$ & $\begin{array}{l}\text { Accuracy } \\
(\%)\end{array}$ & $\begin{array}{l}\mathrm{RSD}_{\mathrm{R}} \\
(\%)\end{array}$ & $\begin{array}{l}\mathrm{RSD}_{\mathrm{T}} \\
(\%)\end{array}$ \\
\hline a-Pinene & 3.8 & 1.8 & 2.7 & $93 / 93$ & $1.2 / \mathbf{1 . 3}$ & $1.4 / 1.4$ & $95 / 96$ & $2.2 / 2.2$ & $3.4 / 2.5$ & $103 / \mathbf{1 0 5}$ & $1.1 / \mathbf{1 . 1}$ & $2.4 / 1.7$ \\
\hline Camphene & 4.5 & 2.2 & 11.0 & $91 / 91$ & $1.7 / \mathbf{0 . 0}$ & $3.3 / \mathbf{2 . 0}$ & $95 / 96$ & $2.3 / \mathbf{2 . 7}$ & $1.8 / \mathbf{1 . 5}$ & $91 / 92$ & $1.8 / \mathbf{1 . 8}$ & $3.7 / 4.4$ \\
\hline$\beta$-Pinene & 5.4 & 1.8 & 5.3 & 93/92 & 1.6/1.6 & $1.8 / \mathbf{1 . 8}$ & $94 / 95$ & $2.7 / 2.7$ & $4.2 / 2.9$ & $103 / 105$ & $1.4 / \mathbf{1 . 4}$ & $3.0 / 2.1$ \\
\hline 3-Carene & 6.5 & 1.6 & 7.3 & $95 / 93$ & $2.0 / \mathbf{2 . 0}$ & $3.2 / \mathbf{2 . 1}$ & $95 / 95$ & $3.1 / 3.1$ & $4.3 / 3.4$ & 104/106 & $1.7 / \mathbf{1 . 7}$ & $3.5 / 2.4$ \\
\hline Limonene & 8.4 & 1.8 & 6.6 & $96 / 94$ & $3.3 / 3.5$ & $2.3 / \mathbf{2 . 8}$ & 97/100 & $3.2 / 3.2$ & $3.1 / 2.2$ & $93 / 96$ & $2.7 / 2.7$ & $6.10 / 6.1$ \\
\hline Bornyl acetate & 22.5 & 1.7 & 2.4 & $92 / 93$ & $4.1 / 4.2$ & $4.0 / 4.6$ & $95 / 96$ & $5.6 / 5.6$ & $8.7 / 6.5$ & 105/107 & $3.3 / 3.3$ & $5.6 / 4.5$ \\
\hline $\begin{array}{l}\beta \text { - } \\
\text { Caryophyllene }\end{array}$ & 22.8 & 2.3 & 2.8 & $101 / 100$ & $4.9 / 5.0$ & $5.1 / 5.7$ & 103/108 & $6.2 / 6.2$ & $5.6 / 3.4$ & 97/100 & $6.2 / 6.2$ & 7.6/9.1 \\
\hline Borneol & 25.5 & 1.7 & 4.3 & $93 / 96$ & $4.3 / 4.5$ & $3.0 / 3.3$ & 97/104 & $4.2 / 4.2$ & $4.0 / 2.3$ & 95/101 & $3.6 / 3.6$ & $5.6 / 6.8$ \\
\hline
\end{tabular}

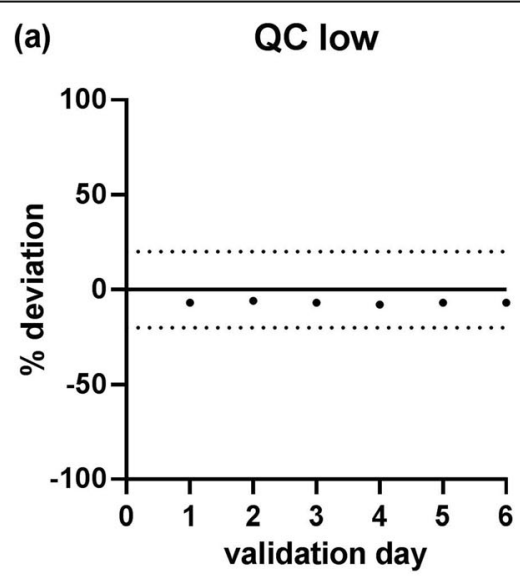

(b)

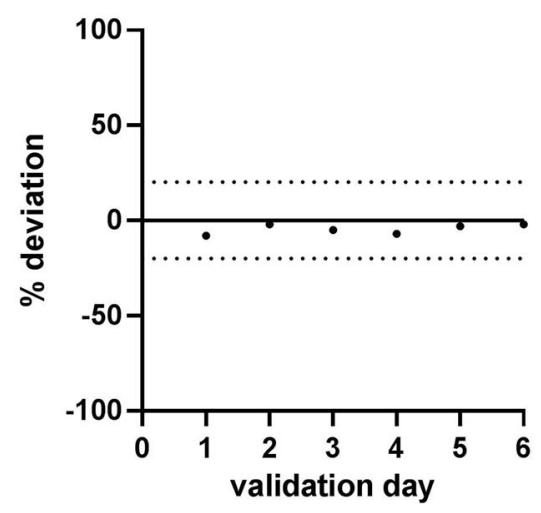

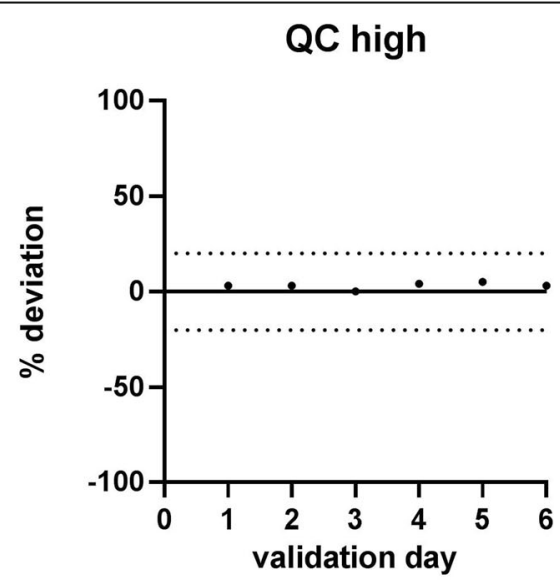

QC high

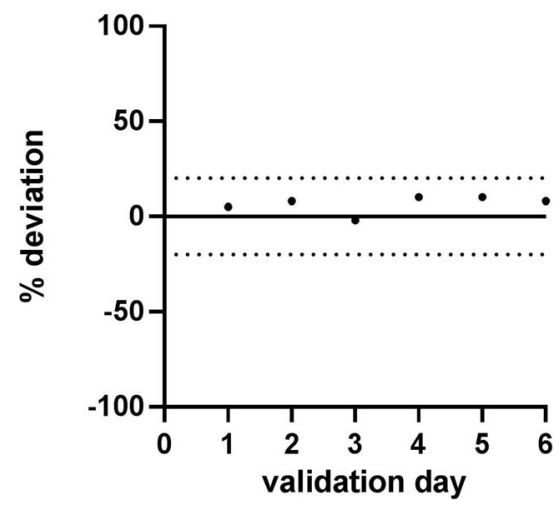

Fig. 3 Stability of calibration of QC low and QC high exemplified of (a) a-pinene and (b) bornyl acetate over six validation days calculated with the calibration equation of the first day. The dotted lines represent an error of $\pm 20 \%$ 
least squares regression model and $\pm 15 \%$ with the RRF method, respectively. The calculated values for accuracy and $\mathrm{RSD}_{\mathrm{R}} / \mathrm{RSD}_{\mathrm{T}}$ of the $\mathrm{QC}$ samples and the values calculated with the RRF method are presented in Table 1 . The accuracy and $\mathrm{RSD}_{\mathrm{R}} / \mathrm{RSD}_{\mathrm{T}}$ were in the ranges of $91-105 \%$ and $<7.6 \%$, respectively. The accuracy and $\mathrm{RSD}_{\mathrm{R}} / \mathrm{RSD}_{\mathrm{T}}$ calculated with the $\mathrm{RRF}$ method were in the ranges of $91-107 \%$ and $<9.1 \%$, respectively. The lower limit of quantification (LLOQ) and upper limit of quantification (ULOQ) were set to the lowest and highest calibration levels, respectively. Regression equations, correlation coefficients $\left(R^{2}\right)$, linear range, retention time robustness, and backcalculated values of the $\mathrm{Cal}$ are listed in Supplementary Table 5S. The obtained correlation coefficients show strong correlation $\left(R^{2} \geq 0.999\right)$ for all terpenes.
The retention times are constant with a RSD of $\leq$ $0.2 \%(=13.2 \mathrm{~s})$ for all terpenes.

The results of the stability tests were in the range of $88-119 \%$. QC med was stable for at least three FT cycles at $-20^{\circ} \mathrm{C}$ (Supplementary, Fig. 1aS). The processed samples were stable for at least $24 \mathrm{~h}$ in the autosampler at ambient temperature (Supplementary, Fig. 1bS). All terpenes were stable over the whole validation time of 6 days (Fig. 3 and Supplementary, Fig. $2 \mathrm{~S})$. The terpenes were stable for 1 month at $-20^{\circ} \mathrm{C}$. The processed and aliquoted $\mathrm{Cal}$ and $\mathrm{QC}$ samples were stable for at least 1 month at $-20^{\circ} \mathrm{C}$, and the stock solutions for the $\mathrm{Cal}$ samples and internal standard (IS) were stable for the same time range at $5{ }^{\circ} \mathrm{C}$ (Supplementary, Table 6S). There is no observed carry-over in the blank samples.

Table 2 Absolute concentration $[\mathrm{mM}]$ of the terpenes and MIC $[\mu \mathrm{g} / \mathrm{mL}](n=3)$ from the tested CEOs against E. coli and S. aureus, n.d. not determined

\begin{tabular}{|c|c|c|c|c|c|c|c|c|c|c|c|}
\hline & $\begin{array}{l}\text { a-Pinene } \\
{[\mathrm{mM}]}\end{array}$ & Camphene & $\beta$-Pinene & 3-Carene & Limonene & Bornyl acetate & $\beta$-Caryophyllene & Borneol & Total & $\begin{array}{l}\text { E. coli } \\
{[\mu \mathrm{g} / \mathrm{mL}]}\end{array}$ & S. aureus \\
\hline CEO1 & 6.0 & 0.1 & 1.1 & 1.0 & 0.9 & n.d. & n.d. & n.d. & 9.1 & $5.2 \pm 1.8$ & $1.6 \pm 0$ \\
\hline CEO2 & 5.0 & n.d. & 2.4 & 1.8 & 1.2 & n.d. & 0.1 & n.d. & 10.5 & $12.5 \pm 0$ & $5.2 \pm 1.8$ \\
\hline CEO3 & 6.8 & n.d. & 1.2 & 1.2 & 0.9 & n.d. & n.d. & n.d. & 10.2 & $12.5 \pm 0$ & $4.7 \pm 2.2$ \\
\hline CEO4 & 5.0 & 0.3 & 4.4 & n.d. & 0.7 & n.d. & 0.1 & n.d. & 10.5 & $37.5 \pm 17.7$ & $12.5 \pm 0$ \\
\hline CEO5 & 3.2 & 0.8 & 0.7 & 2.2 & 1.3 & 1.1 & 0.2 & 0.1 & 9.6 & $37.5 \pm 21.7$ & $33.3 \pm 14.4$ \\
\hline CEO6 & 5.8 & n.d. & 1.1 & 0.8 & 0.7 & 0.3 & n.d. & n.d. & 8.6 & $5.2 \pm 1.8$ & $1.7 \pm 1.4$ \\
\hline CEO7 & 2.1 & 0.2 & 1.2 & 2.7 & 1.0 & n.d. & 0.3 & n.d. & 7.5 & $33.3 \pm 14.4$ & $25 \pm 21.7$ \\
\hline CEO8 & 3.1 & n.d. & 1.3 & 1.4 & 0.9 & 0.3 & 0.1 & n.d. & 7.2 & $6.3 \pm 0$ & $0.9 \pm 0.6$ \\
\hline CEO9 & 3.3 & 0.1 & 1.4 & 1.7 & 1.0 & 0.3 & 0.3 & n.d. & 8.0 & $33.3 \pm 14.4$ & $6.3 \pm 0$ \\
\hline CEO10 & 2.7 & n.d. & 1.4 & 2.0 & 1.4 & 0.3 & 0.4 & n.d. & 8.0 & $50 \pm 0$ & $50 \pm 0$ \\
\hline CEO11 & 2.8 & 0.4 & 1.8 & 0.5 & 0.5 & 0.7 & 0.3 & n.d. & 7.1 & $50 \pm 0$ & $50 \pm 0$ \\
\hline CEO12 & 2.2 & 1.6 & 0.8 & 1.3 & 0.4 & 2.4 & n.d. & 0.1 & 8.8 & $10.4 \pm 3.6$ & $8.3 \pm 3.6$ \\
\hline CEO13 & 1.8 & 1.9 & 0.4 & 0.7 & 0.3 & 3.0 & n.d. & 0.1 & 8.2 & $12.5 \pm 0$ & $12.5 \pm 10.8$ \\
\hline CEO14 & 0.8 & 1.1 & n.d. & n.d. & n.d. & 4.2 & n.d. & 0.3 & 6.3 & $1.2 \pm 0.7$ & $0.29 \pm 0.2$ \\
\hline CEO15 & 1.4 & 2.2 & n.d. & 1.4 & 0.5 & 3.5 & n.d. & 0.2 & 9.2 & $25 \pm 0$ & $12.5 \pm 0$ \\
\hline CEO16 & 1.5 & 2.3 & 0.3 & 1.6 & 0.6 & 2.9 & 0.1 & 0.3 & 9.5 & $50 \pm 0$ & $50 \pm 0$ \\
\hline CEO17 & 1.6 & 2.8 & 0.3 & 1.8 & 0.7 & 3.2 & 0.1 & 0.2 & 10.8 & $25 \pm 0$ & $12.5 \pm 0$ \\
\hline CEO18 & 1.9 & 2.1 & 0.4 & 1.7 & 0.6 & 3.5 & n.d. & 0.2 & 10.5 & $12.5 \pm 0$ & $12.5 \pm 0$ \\
\hline CEO19 & 1.7 & 2.1 & 0.3 & 1.5 & 0.6 & 2.8 & n.d. & 0.2 & 9.3 & $25 \pm 0$ & $25 \pm 0$ \\
\hline CEO20 & 1.4 & 2.2 & n.d. & 1.4 & 0.5 & 3.3 & n.d. & 0.2 & 9.0 & $37.5 \pm 17.7$ & $37.5 \pm 17.7$ \\
\hline CEO21 & 1.8 & 0.8 & 2.5 & 2.8 & 1.0 & 1.5 & n.d. & 0.1 & 10.4 & $50 \pm 0$ & $50 \pm 0$ \\
\hline CEO22 & 3.4 & 0.7 & 0.4 & n.d. & 3.8 & n.d. & 0.1 & n.d. & 8.3 & $50 \pm 0$ & $12.5 \pm 0$ \\
\hline CEO23 & 3.3 & 0.8 & 0.3 & n.d. & 3.4 & n.d. & 0.2 & n.d. & 8.0 & $25 \pm 0$ & $6.25 \pm 0$ \\
\hline CEO24 & 4.7 & 1.2 & 2.6 & n.d. & 2.3 & n.d. & 0.4 & n.d. & 11.1 & $41.7 \pm 14.4$ & $33.3 \pm 14.4$ \\
\hline CEO25 & 1.7 & 0.5 & 3.7 & 1.7 & 0.7 & 0.3 & n.d. & 0.1 & 8.7 & $12.5 \pm 0$ & $3.13 \pm 0$ \\
\hline CEO26 & 9.2 & 0.1 & 2.0 & n.d. & 0.4 & n.d. & 0.1 & n.d. & 11.8 & $50 \pm 0$ & $18.8 \pm 8.8$ \\
\hline Bornyl acetate & & & & & & & & & & $>50 \pm 0$ & $50 \pm 0$ \\
\hline
\end{tabular}




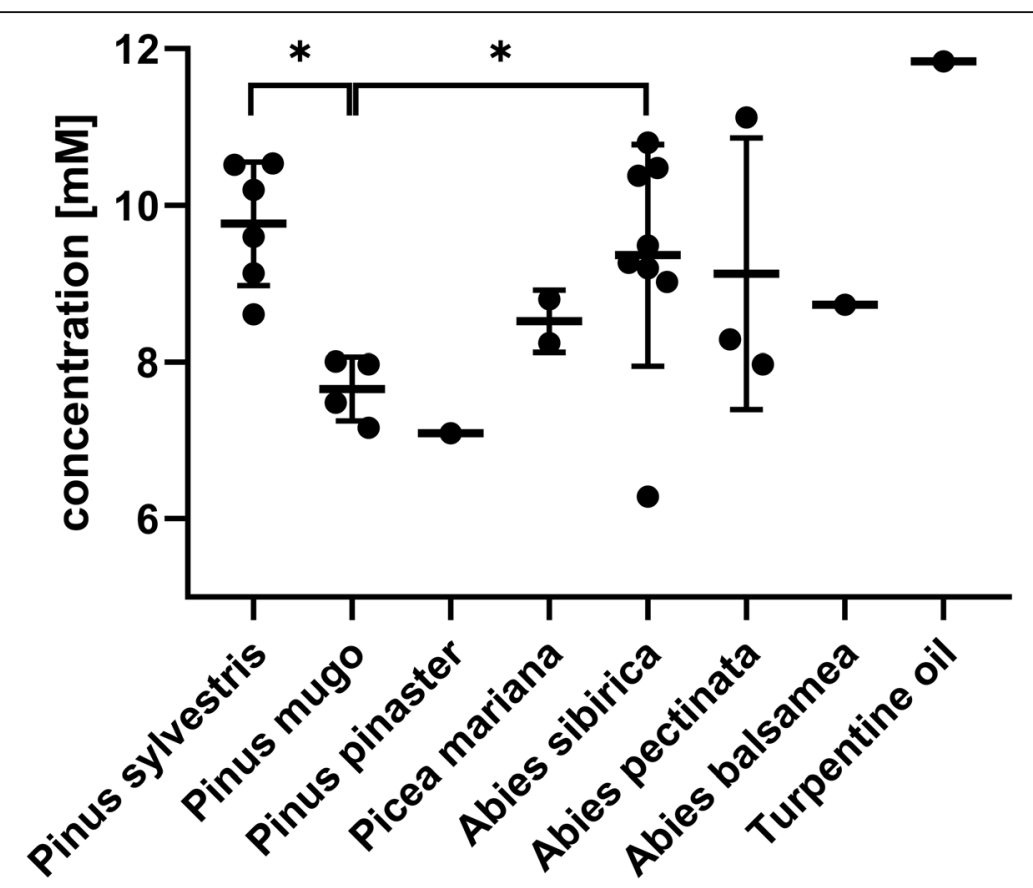

Fig. 4 Total terpene amount of the analyzed CEOs. Significance was tested using an unpaired t-test with $p<0.05\left(^{*}\right)$

The validated method for the absolute quantification is applied to measure the absolute contents of the eight terpenes in the CEOs. GC-FID chromatographic profiles of two CEOs from Pinus sylvestris L. (P. sylvestris) and Abies sibirica L. (A. sibirica) are presented in Supplementary Fig. $3 S$ and Fig. 4S. The values are calculated with the respective RRF and are summarized in Table 2. The shown values are from the diluted samples. The total amount of the terpenes is shown in Fig. 4.

The total amount of the analyzed terpenes ranged from 6.3 to $11.8 \mathrm{mM}$. CEO26 showed the highest terpene amount $(11.8 \mathrm{mM})$ followed by CEO24 $(11.1 \mathrm{mM})$ and CEO17 (10.8 mM). Data were compared using an unpaired $t$ test with $p<0.05$. Statistically significant difference could be observed between $P$. sylvestris and Pinus mugo L. (P. mugo; $p$ value $=0.001)$ and $A$. sibirica and $P$. mugo ( $p$ value $=0.04)$.

The in vitro antibacterial activity of 26 CEOs and bornyl acetate was evaluated by a broth microdilution method using a gram-positive (S. aureus) and a gram-negative (E. coli) microorganism strain. The results of the MIC (assuming $\rho E O=1 \mathrm{mg} / \mathrm{mL}$ ) are shown in Table 2 . The solvent of $5 \%$ DMSO did not inhibit the growth of the tested bacteria. MIC values varied from 0.3 to $50 \mu \mathrm{g} / \mathrm{mL}$ (S. aureus) and $1.2-50 \mu \mathrm{g} / \mathrm{mL}$ (E. coli), respectively.

\section{S. aureus}

All tested CEOs showed antibacterial activity against $S$. aureus. CEO14 was found to possess the highest antibacterial activity (MIC value $0.3 \mu \mathrm{g} / \mathrm{mL}$ ) followed by CEO8 (MIC value $0.9 \mu \mathrm{g} / \mathrm{mL}$ ), CEO1 (MIC value $1.6 \mu \mathrm{g} /$ $\mathrm{mL}$ ), and CEO6 (MIC value $1.6 \mu \mathrm{g} / \mathrm{mL}$ ). These CEOs showed higher antibacterial activity than the positive control ampicillin (MIC value $3.6 \pm 0.6 \mu \mathrm{g} / \mathrm{mL}$ ). The weakest antibacterial activity was obtained by CEO16, CEO21, CEO11, and CEO10 (MIC value $50 \mu \mathrm{g} / \mathrm{mL}$ ).

\section{E. coli}

All investigated EOs inhibit the bacterial growth of $E$. coli whereas CEO14 was found to possess the highest antibacterial activity (MIC value $1.2 \mu \mathrm{g} / \mathrm{mL}$ ). CEO14 shows higher antibacterial activity than the positive control ampicillin (MIC value $5.9 \pm 1.5 \mu \mathrm{g} / \mathrm{mL}$ ).

\section{Discussion}

The absolute quantification was based on the internal standard method using multi-point calibration. The described approach focused on major compounds found in CEOs since full-deck quantification of all terpenes is not feasible due to lack of reference material and detection limits. Based on the previous analysis of the chemical composition of CEOs and the knowledge of their possible antibacterial properties, eight terpenes are chosen for this study (Jagannath et al. 2012). The relative amounts of the selected terpenes in the analyzed CEOs are presented in Supplementary Table 7S. It is obvious from the obtained data that the majority of the chemical composition of the CEOs was covered by the quantified compounds. The used DB-wax column is frequently 
used in the analysis of CEOs and provides good resolution and peak shape of the investigated compounds. The chosen IS was suitable for the quantification since cis-3-hexenol did not co-elute with any compounds of the CEOs and the method shows high accuracy and low imprecision, respectively. This study presents two different approaches during the method validation: the weighted least squares regression model and the RRF approach. Applying both approaches, the validated methods show high accuracy and low imprecision. Using the RRF method, no calibration samples have to be run, whose preparation and analysis is time-, analyte-, and solvent-consuming (green chemistry). Therefore, the RRF method is used for the absolute quantification of target analytes in CEOs. The samples can be frozen and thawed for at least three times and processed samples can be stored at ambient temperature for at least $24 \mathrm{~h}$. $\mathrm{Cal}$ and QC samples and IS can be stored for at least 1 month at $5{ }^{\circ} \mathrm{C}$ and can be used for another preparation of a $\mathrm{Cal}$ and $\mathrm{QC}$ series within this time range. The calibration is stable for at least 6 days. The processed Cal and QC samples can be aliquoted and stored for at least 1 month at $-20^{\circ} \mathrm{C}$. The developed and validated method provides the simultaneous determination of eight important terpenes in CEOs. This approach is widely applicable since GC-FID is ubiquitously available in quality control facilities for essential oils and natural compound analysis.

All CEOs were analyzed accordingly and tested for their antibacterial activity. However, the effectiveness of the inhibition of the bacterial growth varied between the several CEOs. As expected, gram-positive $S$. aureus is more sensitive to the tested CEOs than gram-negative $E$. coli (Burt 2004). Highest activities were observed among the EOs of the species P.sylvestris (CEO1-CEO6) showing on average the highest amount of total terpenes. However, the most effective CEO belongs to the species A. sibirica (CEO14) showing the lowest total amount of terpenes. The data suggest that bornyl acetate plays a crucial role for antibacterial activity. However, bornyl acetate alone does not exhibit a noticeable antibacterial activity. Thus, MICs cannot be fully explained by the concentration of single terpenes but might be the result of synergism among the quantified compounds and/or the compounds present in small concentrations (Sokovic et al. 2010; Delamare et al. 2007). However, there is no particular data suggesting synergism between bornyl acetate and other terpenes. Some studies have demonstrated synergism mainly produced between oxygenated terpenes (Sokovic et al. 2010; Fidan et al. 2019; Bassole and Juliani 2012; Novato et al. 2019; Gavaric et al. 2015; Jagannath et al. 2012). Thus, in further studies, synergism of bornyl acetate with other terpenes should be investigated. Furthermore, results indicated that terpene profiling is crucial. Next to the absolute quantification of the major components, compounds only present in traces should be identified. Accordingly, further studies should examine the sesquiterpene profile of CEOs in detail.

\section{Conclusion}

A simple, reliable, sensitive, accurate, and precise method for the absolute quantification using cis-3-hexenol as IS of $\alpha$-pinene, $\beta$-pinene, 3 -carene, camphene, limonene, bornyl acetate, borneol, and $\beta$-caryophyllene in CEOs was developed and validated by means of GCFID. The method has been successfully applied to analyze the content of these eight terpenes in CEOs. Our data showed that the CEOs possessed effective antibacterial activity against $S$. aureus and E. coli applying a standardized assay format. The absolute quantification enables to compare the effectiveness of the antibacterial activity among the different CEOs. The data indicated that the terpenoid profile is crucial for a comprehensive evaluation of antibacterial activity.

\section{Supplementary information}

Supplementary information accompanies this paper at https://doi.org/10. 1186/s40543-020-00212-y.

\begin{abstract}
Additional file 1: Figure 1S. (a): Freeze thaw stability of QC med at three cycles $(n=3)$. (b): Autosampler stability of QC med at ambient temperature $(n=3)$ A) after 6, 9, 14 and 24 hours. Figure 2S. Stability of calibration of QC low and QC high of (a) camphene, (b) $\beta$-pinene, (c) 3carene, (d) limonene, (e) $\beta$-caryophyllene and ( $f$ ) borneol over six validation days calculated with the calibration equation of the first day. The dotted lines represent an error of $\pm 20 \%$. Figure 3S. Chromatographic profiles of GC-FID of (a) CEO1 (Pinus sylvestris L.) with 1) a-pinene, 2) camphene, 3) $\beta$-pinene, 4) 3-carene, 5) limonene, 6) cis-3-hexenol (IS) and 7) bornyl acetate. Figure 4S. Chromatographic profiles of GC-FID of CEO15 (Abies sibirica L.) with 1) a-pinene, 2) camphene, 3) $\beta$-pinene, 4) 3-carene, 5) limonene, 6) cis-3-hexenol (IS), 7) bornyl acetate, 8) $\beta$-caryophyllene and 9) borneol. Table 1S. Name, in-house code, charge and supplier of the commercial EOs. Table $\mathbf{2} \mathbf{S}$. Chemical properties of the used terpenes and preparation of the stock solutions for Cal and QC samples (dilution solvent: first $2 \mathrm{~mL} \mathrm{EtOH}$, then ad $20 \mathrm{~mL}$ with heptane) and of the IS.

Table 3S. Serial dilution for the Cal and QC samples. Table 4S. Concentrations for Cal and QC samples. All concentrations are given in [mM]. Table 5S. Method validation data: calibration curve, $R^{2}$, linear range, retention time robustness and back-calculation of the Cal $(n=6)$. Data calculated with the RRF are in bold. Table $\mathbf{6 S}$. Long-term stability (1 month) of processed CAL and QC samples at $-20^{\circ} \mathrm{C}(n=2)$. Stock solution stability of the CAL are in bold, n.d. = not determined. Table 7S. Chemical composition (\%, percentages of the total EO composition), -: not detected (peak area $<5000$ or not present).
\end{abstract}

\footnotetext{
Abbreviations

Cal: Calibrator; CEO: Conifer-derived essential oil; Conc: Concentration; DMSO: Dimethyl sulfoxide; EO: Essential oil; E. coli: Escherichia coli; EtOH: Ethanol; FID: Flame ionization detector; GC: Gas chromatography; IS: Internal standard; LLOQ: Lower limit of quantification; LOD: Limit of detection; LOQ: Limit of quantification; MHII: Mueller Hinton II Broth; MIC: Minimum inhibitory concentration; PA: Peak area; Ph. Eur.: European Pharmacopeia; RF: Response factor; RRF: Relative response factor; RSD: Relative standard deviation; $\mathrm{RSD}_{\mathrm{R}} / \mathrm{RSD}_{\mathrm{T}}$ : Intra- and interday precision; $S$. aureus: Staphylococcus aureus; S/N: Signal-to-noise ratio; T: Terpene; ULOQ: Upper limit of quantification; QC: Quality control
} 


\section{Acknowledgements}

The authors would like to thank Danielle Lüthi (Institute of Pharmaceutical Analytics, ETH Zurich) for the analytical support as well as Dr. Katja Zerbe and Myriam Gwerder for the introduction in antibacterial testing.

\section{Authors' contributions}

MDA prepared and analyzed all biological samples. CV and CS designed the study protocol. MDA and CS interpreted all obtained data and were major contributors in writing the manuscript. All authors read and approved the final manuscript.

\section{Funding}

This research did not receive any specific grant from funding agencies in the public, commercial, or not-for-profit sectors.

\section{Availability of data and materials}

All data generated or analyzed during this study are included in this published article and its supplementary information files.

\section{Competing interests}

In accordance with the policies of the companies, CV is working for (Systema Natura $\mathrm{GmbH}$, Symaplant $\mathrm{GmbH}$ ) and her ethical obligation as a researcher, $\mathrm{CV}$ is reporting that this research may lead to the development of products in which CV has a business interest. CV has disclosed those interests fully to ETH Zürich and has in place an approved plan for managing any potential conflicts arising from this arrangement.

\section{Author details}

'Institute of Pharmaceutical Sciences, ETH Zürich, Vladimir-Prelog-Weg 4, CH-8093 Zürich, Switzerland. ${ }^{2}$ Systema Natura GmbH, Flintbek, Germany.

\section{Received: 19 February 2020 Accepted: 6 April 2020}

\section{Published online: 19 April 2020}

\section{References}

Armbruster DA, Pry T. Limit of blank, limit of detection and limit of quantitation. Clin Biochem Rev. 2008;29(Suppl 1):S49-52.

Bagci E, Digrak M (1996) Antimicrobial activity of essential oils of some Abies (Fir) species from Turkey. Flavour Frag J 11 (4):251-256. doi:10.1002/(Sici)10991026(199607)11:4 < 251::Aid-Ffj577 > 3.0.Co;2-K.

Başer KHC, Buchbauer G (2016) Handbook of essential oils: science, technology, and applications. Second edition. edn. CRC Press, Taylor \& Francis Group, Boca Raton.

Bassole IHN, Juliani HR. Essential oils in combination and their antimicrobial properties. Molecules. 2012;17(4):3989-4006. https://doi.org/10.3390/ molecules 17043989.

Bicchi C, Liberto E, Matteodo M, Sgorbini B, Mondello L, Zellner BD, Costa R, Rubiolo P. Quantitative analysis of essential oils: a complex task. Flavour Frag J. 2008;23(6):382-91. https://doi.org/10.1002/ffj.1905.

Bouyahya A, Belmehdi O, Abrini J, Dakka N, Bakri Y. Chemical composition of Mentha suaveolens and Pinus halepensis essential oils and their antibacterial and antioxidant activities. Asian Pac J Trop Med. 2019;12(3):117-22. https:// doi.org/10.4103/1995-7645.254937.

Burt S. Essential oils: their antibacterial properties and potential applications in foods--a review. Int J Food Microbiol. 2004;94(3):223-53. https://doi.org/10. 1016/j.ijfoodmicro.2004.03.022.

Chouhan S, Sharma K, Guleria S. Antimicrobial activity of some essential oilspresent status and future perspectives. Medicines (Basel). 2017;4(3). https:// doi.org/10.3390/medicines4030058.

Dahham SS, Tabana YM, Iqbal MA, Ahamed MB, Ezzat MO, Majid AS, Majid AM. The anticancer, antioxidant and antimicrobial properties of the sesquiterpene beta-caryophyllene from the essential oil of Aquilaria crassna. Molecules. 2015;20(7):11808-29. https://doi.org/10.3390/molecules200711808.

Delamare APL, Moschen-Pistorello IT, Artico L, Atti-Serafini L, Echeverrigaray S. Antibacterial activity of the essential oils of Salvia officinalis $L$. and Salvia triloba L. cultivated in South Brazil. Food Chem. 2007;100(2):603-8. https:// doi.org/10.1016/j.foodchem.2005.09.078.

Demirbolat I, Kartal M, Karik U (2019) Development and validation of a GC-FID method to quantify thymoquinone in black cumin seed oils. J Res Pharm 23 (3):506-513. doi:10.12991/jrp.2019.157.
Edris AE. Identification and absolute quantification of the major water-soluble aroma components isolated from the hydrosols of some aromatic plants. J Essent Oil Bear PI 12 (2):155-161. doi:Doi. 2009. https://doi.org/10.1080/ 0972060x.2009.10643705.

Fahed L, Khoury M, Stien D, Ouaini N, Eparvier V, El Beyrouthy M. Essential oils composition and antimicrobial activity of six conifers harvested in Lebanon. Chem Biodivers. 2017;14(2). https://doi.org/10.1002/cbdv.201600235.

Fidan H, Stefanova G, Kostova I, Stankov S, Damyanova S, Stoyanova A, Zheljazkov VD (2019) Chemical composition and antimicrobial activity of Laurus nobilis L. Essential Oils from Bulgaria. Molecules 24 (4). doi:ARTN 804153390/molecules24040804.

Gavaric N, Mozina SS, Kladar N, Bozin B. Chemical profile, antioxidant and antibacterial activity of thyme and oregano essential oils, Thymol and Carvacrol and Their Possible Synergism. J Essent Oil Bear PI. 2015;18(4):101321. https://doi.org/10.1080/0972060x.2014.971069.

Guimaraes AC, Meireles LM, Lemos MF, Guimaraes MCC, Endringer DC, Fronza M, Scherer R (2019) Antibacterial activity of terpenes and terpenoids pesent in essential oils. Molecules 24 (13). doi:ARTN 2471183390/molecules24132471.

Hong EJ, Na KJ, Choi IG, Choi KC, Jeung EB. Antibacterial and antifungal effects of essential oils from coniferous trees. Biol Pharm Bull. 2004;27(6):863-6.

Ibrahim EA, Wang M, Radwan MM, Wanas AS, Majumdar CG, Avula B, Wang YH, Khan IA, Chandra S, Lata H, Hadad GM, Salam RAA, Ibrahim AK, Ahmed SA, ElSohly MA. Analysis of terpenes in Cannabis sativa L. Using GC/MS: method development, validation, and application. Planta Med. 2019;85(5):431-8. https://doi.org/10.1055/a-0828-8387.

International Conference on Harmonization (ICH). Validation of analytical procedures. Text and Methodology Q2 (R1) 1996.

Iseppi R, Brighenti V, Licata M, Lambertini A, Sabia C, Messi P, Pellati F, Benvenuti S. Chemical characterization and evaluation of the antibacterial activity of essential oils from fibre-type Cannabis sativa L. (Hemp). Molecules. 2019; 24(12). https://doi.org/10.3390/molecules24122302.

Jagannath N, Ramakrishnaiah H, Krishna V, Gowda PJ. Chemical composition and antimicrobial activity of essential oil of Heracleum rigens. Nat Prod Commun. 2012;7(7):943-6.

Lee JH, Lee BK, Kim JH, Lee SH, Hong SK. Comparison of chemical compositions and antimicrobial activities of essential oils from three conifer trees; Pinus densiflora, Cryptomeria japonica, and Chamaecyparis obtusa. J Microbiol Biotechnol. 2009a;19(4):391-6.

Lee JH, Lee BK, Kim JH, Lee SH, Hong SK. Comparison of chemical compositions and antimicrobial activities of essential oils from three conifer trees; Pinus densiflora, Cryptomeria japonica, and Chamaecyparis obtusa. J Microbiol Biotechn. 2009b;19(4):391-6. https://doi.org/10.4014/jmb.0803.191.

Lee JH, Yang HY, Lee HS, Hong SK. Chemical composition and antimicrobial activity of essential oil from cones of Pinus koraiensis. J Microbiol Biotechnol. 2008;18(3):497-502.

Lim V, Narawi MM, Chiu HI, Tung WH, Tan JJ, Lee CK. Selected essential oils as repellents against Aedes Aegypti: validation of the bioconstituents using gas chromatography. J Essent Oil Bear PI. 2019;22(4):1058-73. https://doi.org/10. 1080/0972060x.2019.1661796.

Mudge EM, Brown PN, Murch SJ. The terroir of Cannabis: terpene metabolomics as a tool to understand Cannabis sativa selections. Planta Med. 2019;85(9-10): 781-96. https://doi.org/10.1055/a-0915-2550.

Nazzaro F, Fratianni F, De Martino L, Coppola R, De Feo V. Effect of essential oils on pathogenic bacteria. Pharmaceuticals. 2013;6(12):1451-74. https://doi.org/ 10.3390/ph 6121451.

Novato TLP, Marchesini P, Muniz N, Prata MCA, Furlong J, Vilela FMP, Daemon E, Maturano R, Monteiro C. Evaluation of synergism and development of a formulation with thymol, carvacrol and eugenol for Rhipicephalus microplus control. Exp Parasitol. 2019;207:107774. https://doi.org/10.1016/j.exppara.2019. 107774.

Park JS, Lee GH. Volatile compounds and antimicrobial and antioxidant activities of the essential oils of the needles of Pinus densiflora and Pinus thunbergii. J Sci Food Agr. 2011;91(4):703-9. https://doi.org/10.1002/jsfa.4239.

Pichette A, Larouche PL, Lebrun M, Legault J. Composition and antibacterial activity of Abies balsamea essential oil. Phytother Res. 2006;20(5):371-3. https://doi.org/10.1002/ptr.1863.

Russo EB. Taming THC: potential cannabis synergy and phytocannabinoidterpenoid entourage effects. Brit J Pharmacol. 2011;163(7):1344-64. https:/ doi.org/10.1111/j.1476-5381.2011.01238.x.

Sarac Z, Matejic JS, Stojanovic-Radic ZZ, Veselinovic JB, Dzamic AM, Bojovic S, Marin PD. Biological activity of Pinus nigra terpenes--evaluation of FtsZ 
inhibition by selected compounds as contribution to their antimicrobial activity. Comput Biol Med. 2014;54:72-8. https://doi.org/10.1016/j. compbiomed.2014.08.022.

Sokovic M, Glamoclija J, Marin PD, Brkic D, van Griensven LLLD. Antibacterial effects of the essential oils of commonly consumed medicinal herbs using an in vitro model. Molecules. 2010;15(11):7532-46. https://doi.org/10.3390/ molecules15117532.

\section{Publisher's Note}

Springer Nature remains neutral with regard to jurisdictional claims in published maps and institutional affiliations.

Submit your manuscript to a SpringerOpen ${ }^{\mathcal{O}}$ journal and benefit from:

- Convenient online submission

Rigorous peer review

- Open access: articles freely available online

- High visibility within the field

- Retaining the copyright to your article

Submit your next manuscript at $\boldsymbol{\wedge}$ springeropen.com 